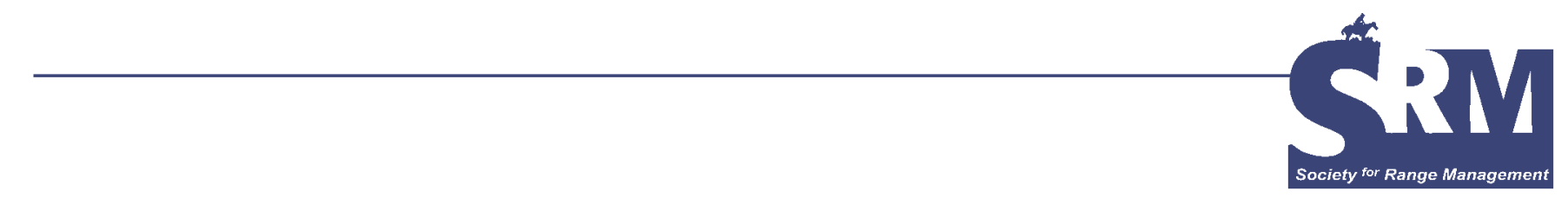

\title{
Controlling Annual Bromes
}

\section{Using rangeland "greenstrips" to create natural fire breaks.}

\section{By Derek Miller}

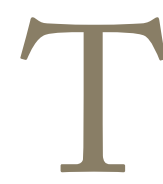

he skyrocketing costs of fire suppression in the western United States are driving land managers and government agencies to seek effective, longterm methods for reducing fire threats. In 2003, the US Forest Service spent $\$ 1.2$ billion fighting wildfires, costing taxpayers more per acre than any other season in history. With heavy moisture in the West, the 2005 and 2006 seasons are predicted to be worse. To control the mounting costs of wildfires, a growing number of land managers and government officials are looking to innovative fire management techniques, such as "greenstripping," the creation of

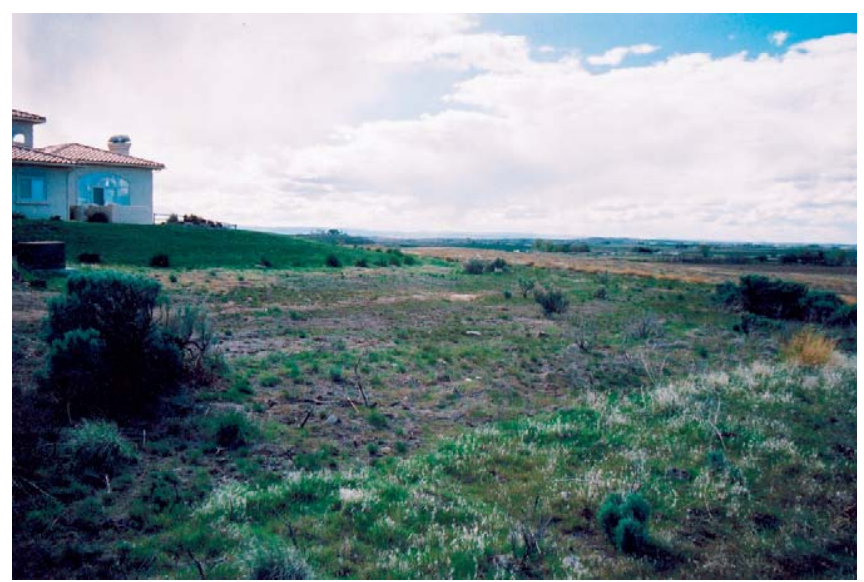

Greenstripping near houses can minimize the chance that a wildfire will damage property and endanger homeowners. long, narrow bands of fire-retardant vegetation that serve as natural fire breaks.

\section{Eliminating Fine Fuels}

Greenstrips, which introduce fire-resistant broadleaf plants and grasses in areas prone to wildfires, can be a particularly effective fire-prevention tool in the West, where millions of acres of range and prairie lands are today dominated by fire-prone invasive weed species, such as medusahead and cheatgrass.

Because such nonnative species dry earlier in the season than native plants, they play a key role in the growth and spread of massive wildfires, providing fine ignition fuel that enables rangeland fires to burn faster, further, and longer.

Cheatgrass is fine-textured and flattens to form a continuous mat on the ground; it can dramatically increase fire danger. Conversely, native Western species, such as lowgrowing sagebrush, serviceberry, bitterbrush, rabbitbrush, and perennial bunchgrasses, typically hold moisture throughout a season, are rough-textured and do not create a continuous mat, and form natural firebreaks that can slow or stop the spread of fire.

\section{Restoring Nature's Cycle}

Although wildfires have always been a natural part of the sagebrush-grassland ecosystem, such fires have historically only occurred at intervals of 60 to 100 years, typically burning only a few hundred acres. Today, with millions of 


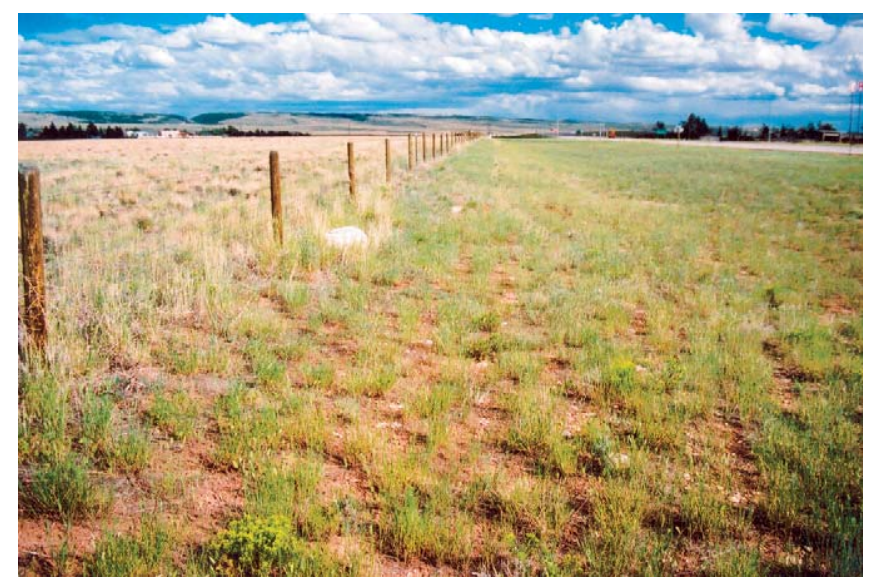

The area to the right of the fence in this photo has been treated with herbicide to create a greenstrip that acts as a natural fire break.

rangeland acres infested by invasive weeds, the picture is much different.

Rangelands infested with cheatgrass typically burn every 3 to 5 years, consuming hundreds of thousands of acres in a single wildfire. The fires destroy native plants, which are often replaced entirely by nonnative species, creating a monoculture that makes it virtually impossible for native plants to naturally reestablish themselves.

\section{Greenstrips Form Natural Fire Barriers}

Greenstrips work by combining careful vegetation management strategies with prudent land management to reduce the fuels and conditions that lead to massive wildfires. Plants in a greenstrip are normally widely spaced, with little or no fuel growing in between; therefore, if 1 plant is ignited, fire cannot as easily spread to nearby plants.

In areas prone to wildfire, greenstrips can be particularly helpful in slowing the fire's spread. Creating natural fire breaks, greenstrips help form barriers and anchor points where firefighters can more safely and effectively fight an expanding fire.

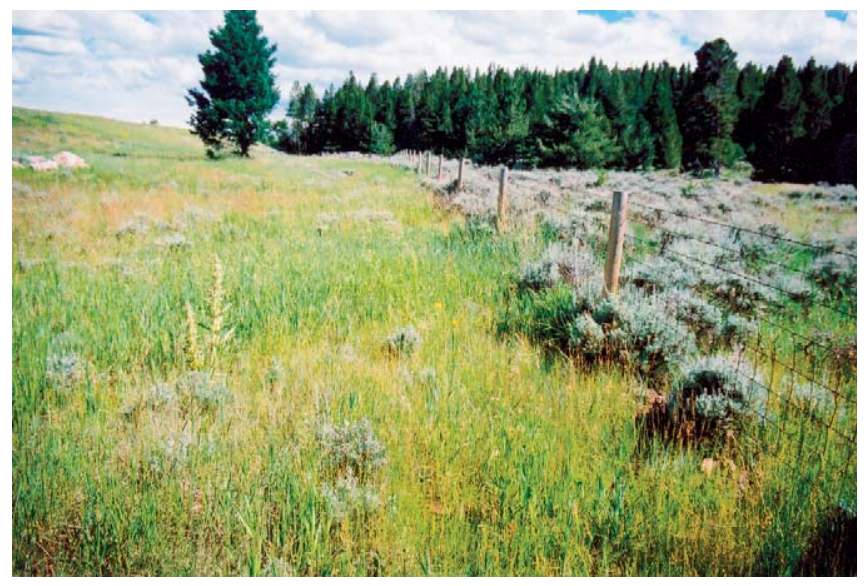

Greenstripping-the creation of long, narrow bands of fire-retardant vegetation-helps create natural fire breaks on rangeland. The area to the left of the fence in this photo shows how herbicides can be used to control fire-fuel vegetation.
Key Questions to Consider in Establishing a Successful Greenstrip

Before you begin the steps needed to establish a successful greenstrip, be sure to consider several key questions that can have a significant impact on the size and scope of your project:

- How wide will your greenstrip need to be?

- What type of vegetation needs to be removed to reduce flammability and flame height?

- Will reseeding be needed after brush removal, or does the area contain adequate fire-resistant vegetation?

- Is the area prone to cheatgrass invasion? Or, is the area already populated by cheatgrass?

The answers to these key questions can be found by consulting your local extension agent, Natural Resources Conservation Service (NRCS) office, or visiting the Firewise Web site at http://www.firewise.org, which contains key guidance from the National Wildfire Coordinating Group, a consortium of wildland fire agencies.

To determine whether or not your proposed greenstrip has the potential for cheatgrass invasion after brush removal or seedbed preparation, consult your local Department of Natural Resources (DNR) or state game department. If the potential for cheatgrass invasion exists, most experts will strongly recommend using an herbicide for cheatgrass control.

Because they are typically populated by plants with higher moisture content than nonnative species, such as cheatgrass, greenstrips can dramatically reduce the speed at which a fire moves. The associated drop in fire intensity and speed can give firefighters a better opportunity to control and extinguish the blaze. Greenstrips can also:

- Improve fire control in high-risk areas. Along roads and railways, where cigarettes from cars or sparks created by passing trains can ignite fires, greenstrips can help prevent ignition or slow the spread of fire.

- Protect local communities. Creating a fire-fuel break around an urban area can dramatically reduce property losses from a rangeland fire. Used around individual homes or neighborhoods, greenstrips can break up blocks of flammable nonnative vegetation.

- Restore natural habitat. By eliminating invasive species, such as cheatgrass, greenstrips can help improve wildlife populations and restore native plant habitats, protecting winter rangeland for mule deer and habitat for threatened species such as sage grouse.

Greenstrip Species and Size Varies by Region Typically, the specific plant species used to create a greenstrip will depend on the region in which the barrier is established. 


\section{Site Preparation and Seeding}

Establishing a greenstrip generally involves a 3-step process: first, removing existing vegetation; then, preparing a seedbed; and finally, seeding desired native plants.

\section{Removing Existing Vegetation}

The first step involves preparing the site by removing existing vegetation that acts as ignition or ladder fuel. Removal of brush has often resulted in release of annual invasive weeds, basically switching one fuel for another more flammable fuel. It is particularly important to eliminate competition from invasive weeds, giving newly seeded plants improved access to light, moisture and nutrients. Landowners and managers typically use one or more of the following site-preparation methods to remove existing vegetation:

1. Mechanical methods: Using mowing or chipping or similar techniques to eliminate unwanted brush. Disking and cultipacking-a method that packs seeds into the ground to encourage good seed-soil contact-can be used to aid in preparing the land for reseeding, but this is not usually necessary.

2. Intensive grazing, mowing and raking, or controlled burns: These techniques reduce the amount of undesirable weeds and ground cover, opening the space for desired vegetation.

3. Application of selective residual herbicides: This step can specifically target invasive weeds to provide long-term control, helping to eliminate fire fuel and competition and to improve growth rates for reseeded vegetation.

\section{Preparing a Seedbed}

Proper seedbed preparation methods will likely vary depending on the region, terrain, and resources in which the greenstrip is established, but common seedbed techniques generally involve preparing the soil for drill seeding and applying an herbicide to eliminate plant competition.

\section{Herbicides Can Boost Greenstrip Effectiveness}

In preparing a site for seeding, low-volume herbicides, such as Plateau herbicide or Journey herbicide from BASF, have proven to be effective in preparing greenstrips overgrown with cheatgrass. Such herbicides can control cheatgrass (which seeks to create a monoculture) while still allowing desirable native plants to flourish.

Low-volume herbicides can be used in site-preparation treatments and are especially effective for control of cheatgrass, when used in conjunction with a competitive plant reseeding program. Reseeding can be done immediately after herbicide application.

A 2002 study by Synergy Resource Solutions Inc and BASF shows that fire intensity and spread can be significantly reduced in areas where cheatgrass was removed using herbicides. The height of flames in treated areas can be reduced by as much as $88 \%$, and the rate at which fire spreads can be lowered by as much as 95\% when compared with untreated areas.

Research shows that the use of herbicide can help lower biomass, decrease plant litter, and increase space between plants-desirable outcomes in creating a successful greenstrip area.

\section{Fall Application Is Recommended}

When used for controlling cheatgrass and creating greenstrip areas, Plateau herbicide works best when applied in the fall, before cheatgrass germination. Journey herbicide can be applied for cheatgrass control anytime before reseeding.

Application rates are determined by several different factors. These factors include climate, tolerance of existing desirable species, soil type, length of soil activity desired, amount of cheatgrass seed already in the soil, and the amount of plant litter on the ground. Consult product labels for rate information.

\section{Seeding Desired Native Plants}

No-till drills can enable precise control over the amount and depth at which seeds are planted. This is generally considered the best method for seeding a greenstrip.

Terrain and brush removal techniques can result in the need for a rangeland drill to better accommodate the conditions. However, drilling is not always feasible, particularly in hard-to-access areas.

In rough terrain, land managers may need to use an aerial seeding method, followed by chaining or another method to cover the seed. This step helps protect seeds from wind and water erosion. Aerial seeding followed by chaining can also be more practical when establishing greenstrips over a very large acreage because the method is generally faster than drill seeding.

Plateau is a registered trademark of BASF. Journey is a trademark of BASF.

(c) 2006 BASF Corporation.

All Rights Reserved. 
Greenstrips planted in Nevada, for example, will likely contain species that are far different from those in the state of Washington because of variations in climate and soil conditions. However, in establishing a greenstrip, land managers generally select plant species that will:

- Readily establish themselves after planting

- Be difficult to ignite

- Burn with low intensity

Species that grow low to the ground are ideal for greenstrips. Therefore, if a fire occurs, it is less likely to spread flames or embers to neighboring areas. Another option is to use brush-type species with high moisture content-plants that tend to stay lush and green during fire season. The most effective selections are fire-resistant plants, preferably native species that help suppress fire and are capable of thriving with little supervision.

The length and width of a greenstrip generally depends on where it will be planted and the types of plants that are native to the region. For example, in a flat area, typically populated by wildland grasses, a greenstrip 30 feet wide may be adequate.

Conversely, in Pinyon-Juniper areas, with steep slopesareas in which fire sparks and embers can spread from treetop to treetop-greenstrips may need to be substantially wider, perhaps as wide as 200 feet.

Man-made fuel breaks such as roads and railways can help reduce the required width of the greenstrip planting. Natural fire breaks, such as streams or rocky areas, can also be incorporated to reduce greenstrip width.

For recommendations on what species and strategies may work best for greenstrips in specific communities or regions, contact your nearest Natural Resources Conservation Service. Local service center contact information is available on the agency's Web site at http://www.nrcs.usda.gov.

Author is BASF Professional Vegetation Management marketing manager, Raleigh, NC 27709, millerdw@basf.com. 